\title{
Is Free Speech in Danger on University Campus? Some Preliminary Evidence from a Most Likely Case
}

\author{
Matthias Revers $\cdot$ Richard Traunmüller
}

Received: 27 November 2019 / Accepted: 23 September 2020 / Published online: 26 October 2020

(C) The Author(s) 2020

\begin{abstract}
Although universities play a key role in questions of free speech and political viewpoint diversity, they are often associated with the opposite of a free exchange of ideas: a proliferation of restrictive campus speech codes, violent protests against controversial speakers and even the firing of inconvenient professors. For some observers these trends on university campuses are a clear indicator of the dire future for freedom of speech. Others view these incidents as scandalized singular events and regard campus intolerance as a mere myth. We take an empirical look at some of the claims in the debate and present original survey evidence from a most likely case: the leftist social science studentship at Goethe University Frankfurt. Our results show that taking offense is a common experience and that a sizable number of students are in favor of restricting speech on campus. We also find evidence for conformity pressures on campus and that both the desire to restrict speech and the reluctance to speak openly differ significantly across political ideology. Leftleaning students are less likely to tolerate controversial viewpoints and right-leaning students are more likely to self-censor on politically sensitive issues such as gender, immigration, or sexual and ethnic minorities. Although preliminary, these findings may have implications for the social sciences and academia more broadly.
\end{abstract}

Keywords Freedom of expression - Viewpoint diversity · Higher education · Political ideology $\cdot$ Tolerance

\footnotetext{
M. Revers $(\bowtie)$

School of Media and Communication, University of Leeds

Leeds, LS2 9JT, UK

E-Mail: m.revers@leeds.ac.uk

R. Traunmüller

School of Social Sciences, Chair of Political Science Empirical and Democracy Research, University of Mannheim

Building A, 68159 Mannheim, Germany

E-Mail: traunmueller@uni-mannheim.de
} 


\section{Ist die Meinungsfreiheit an der Universität in Gefahr? Einige vorläufige Befunde anhand eines ,Most likely case“}

Zusammenfassung Obwohl Universitäten eine Schlüsselrolle in Fragen der Meinungsfreiheit und Meinungsvielfalt zukommt, werden sie in der Öffentlichkeit oftmals mit dem genauen Gegenteil assoziiert: einer Häufung restriktiver Sprachregelungen, gewalttätigen Protesten gegen umstrittene Redner und Suspendierung unbequemer Professoren. Manche Beobachter sehen darin beunruhigende Anzeichen für eine dunkle Zukunft der Meinungsfreiheit. Andere betrachten diese Vorfälle dagegen als skandalisierte Einzelereignisse und halten studentische Intoleranz für einen Mythos. Wir widmen uns diesen Behauptungen empirisch und stellen erste Befunde eines „Most likely case“ vor: der linken Studentenschaft der Sozialwissenschaften in Frankfurt. Unsere Umfrageergebnisse zeigen, dass sich Studierende häufig sprachlich angegriffen fühlen und dass sich ein beträchtlicher Anteil für die Einschränkung der Meinungsfreiheit ausspricht. Auch finden wir Hinweise für Konformitätsdruck. Sowohl hinsichtlich des Wunsches, die Redefreiheit einzuschränken als auch hinsichtlich der Hemmung, seine Meinung offen zu äußern, bestehen politisch-ideologische Unterschiede. Linksgerichtete Studierende sind weniger bereit, umstrittene Standpunkte zu Themen wie Gender, Einwanderung oder sexuelle und ethnische Minderheiten zu tolerieren. Studierende rechts der Mitte neigen eher dazu, sich selbst zu zensieren. Obwohl diese Befunde vorläufiger Natur sind, weisen sie möglicherweise auf Probleme innerhalb der Sozialwissenschaften und dem universitären Kontext hin.

Schlüsselwörter Freie Meinungsäußerung · Meinungsvielfalt · Hochschulbildung · Politische Ideologie · Toleranz

\section{Introduction}

Universities play a key role in questions of free speech and political viewpoint diversity (Chong 2006; Lea 2009; Lukianoff and Haidt 2018; Baer 2019). Not only are universities central places for the intellectual exchange of ideas and the debate of issues of societal relevance, they are also laboratories for new standards and norms of speech that eventually diffuse into the wider public. In addition to research and teaching, universities are also responsible for the civic education of students. Students must learn to form well-founded opinions and to defend them with factual arguments in open debates. A requirement of this is that they are exposed to a variety of opposing views and compelled to wrestle with a range of counterarguments.

For these reasons, it is all the more alarming that universities have recently received public attention for the exact opposite of a free exchange of ideas. Issues that have caught the attention of news media range from a proliferation of increasingly intricate campus speech codes, over disinvitations and violent protests against controversial speakers, to the forced resignation, demotion, and firing of professors. 
Additionally, as we will show below, these developments are by no means restricted to the English-speaking world.

Although the critique of these trends on university campuses is not limited to conservative voices as it was in the 1990s (e.g., Etzioni 2014; Lilla 2016; Lukianoff and Haidt 2018), a common thread that runs through the debate is a political divide. One side sees universities as places dominated by left-leaning students and faculty who, supported by university administrations, shut down speech in the name of antidiscrimination and are intolerant of dissenting views, most notably those considered conservative (Dow and Lendler 2002). They worry about a stifling atmosphere in which members of the institution must be increasingly careful of what they say or write.

Other voices are more critical of these campus controversies. They view them as singular scandalized events and a problem only among a small minority of radical students. To them, campus intolerance in the wider sense does not exist but is a construct of the political right (Wilson 1995; Feldstein 1997). For these observers, the main purpose of the debate is to discredit attempts to fight discrimination and to make the university a safer learning environment for an increasingly diverse student body.

What unites both positions, however, is a relative lack of systematic empirical evidence to support their claims about the current state of free speech and viewpoint diversity on university campuses (but see Stevens and Haidt 2018a, 2018b, 2018c; for a notable exception). In this paper, we aim to contribute to this debate through the exploration of some preliminary empirical evidence from the German university context. In particular, we are interested in answering the following questions: What do students consider offensive speech to be and how tolerant are they of controversial viewpoints? Is there evidence for social pressure to conform to 'political correctness' (PC) and does this restrict free discussion on university campus? Are left-leaning students truly more willing to restrict what can be said on campus? And are right-leaning students more reluctant to speak openly than their left-leaning peers?

Our empirical analysis is based on original survey data collected from social science students at Goethe University Frankfurt. We are certainly not under the impression that our sample is representative of university students in general (or the wider public, for that matter). On the contrary, we purposefully consider the social science studentship at Frankfurt as a most likely case (George and Bennett 2005; Gerring 2007). First, the University of Frankfurt became a focal point of the leftist student movement in the 1960s and still has a reputation as being a training ground for the political left. Second, as the birthplace of the Frankfurt School of critical theory, the university is traditionally associated with the activist rather than the scientific impetus of the social sciences. Third, teaching and research at Frankfurt puts great emphasis on ideas that directly relate to the control of undesired speech: cultural recognition as a means of redistributive justice; to treat speech as a type of action (speech act theory); standpoint theory, which seeks to amplify oppressed voices; and intersectionality which evaluates discrimination according to the cumu- 
lative disadvantage of overlapping identities. ${ }^{1}$ Finally, even students take note of the idiosyncratic discussion culture at Frankfurt. ${ }^{2}$

Thus, our reasoning is simple: If we were unable to detect tendencies for the restriction of speech in our sample, it would be unlikely to find such evidence anywhere else. If this turned out to be the case, we would be in a good position to dismiss claims of a repressive discursive climate on university campuses. If, however, we uncovered empirical evidence for the undue suppression of speech and selfcensorship in our sample, the hypothesis would have to be upheld and scrutinized in other university contexts. In addition, and importantly, a broader discussion of viewpoint diversity in the social sciences would be in order.

Our preliminary results give few reasons to be optimistic. We show that taking offense is a common experience and that a sizable number of students are in favor of restricting free speech on university campus. Depending on the topic of discussion, between one-third and half of the students would not allow a controversial speaker on campus and even higher numbers think that such individuals should not be allowed to teach at the university. Roughly one-third of students are also in favor of banning controversial books from their university library. Furthermore, we find evidence for conformity pressures on campus. One-quarter of all students report personal attacks for voicing an unpopular opinion and one-third feel reluctant to openly give their view on controversial political topics in class discussions. Both the desire to restrict speech and the reluctance to speak openly differ significantly across political ideologies. Left-leaning students are less likely to tolerate controversial speakers, teachers or books at the university on politically sensitive issues such as gender, immigration, or sexual and ethnic minorities. Right-leaning students are more likely to self-censor on these topics, are more concerned about the consequences of expressing political views, and are more likely to be criticized for doing so.

Some points of clarification are important to put these results in perspective. First, our tolerance measures focus on very specific topics: gender equality, homosexuality, Islam, and immigration. Although these topics lie at the center of the current campus controversy, they also tap into the sensitivities of the left. As one can only tolerate what one rejects (Sullivan et al. 1979), the fact that right-leaning students appear more "tolerant" may be simply due to the fact that they are either indifferent to or even agree with the controversial statements. This could very well be the case for criticism of Islam and immigration, which figures prominently in the political discourse on the right. Clearly, we could think of other controversial ideas that students on the right would find objectionable (e.g., abortion or the expropriation of the rich) and therefore less willing to tolerate. We discuss the implications of these

\footnotetext{
1 We do not intend to caricature or disparage these theories but merely expose how they are employed in campus discussions, including as justification to silence voices.

2 As one of them put it in our survey, "this is only in Frankfurt. In Augsburg, you could explore whatever you thought and discuss it with other students and the professor. Frankfurt has horrible people when it comes to sensitive topics." The bitter irony of the extent to which pressures of conformity pervade the intellectual birthplace of critical theory has not escaped participants in our study: "I actually found the point ... amusing, about this university [being] known for critical thinking, so left-wing people come here so that they can critically think among themselves.".
} 
particular measures of tolerance again in the literature review, the methods section, and in the final discussion.

Second, our student sample exhibits a very strong ideological skew to the left. The median score on the standard left-right scale (which runs from 0 to 10 ) is 3 . Half of our students openly identify as 'left-wing' - but only $1 \%$ identify as straight-out "right-wing". Although we have no reason to doubt that this reflects the ideological distribution in our specific student population, it also skews our comparison. We are essentially comparing extremely left-leaning with only moderately right-leaning students.

Our point, therefore, is not to make sweeping statements about the tolerance of the political left or the right in general but to look empirically at a very specific allegation of intolerance leveled at leftist students. With these important caveats in mind, our results still indicate worrying tendencies in academic culture that may have implications for university students and teachers, as well as the social sciences more broadly. We consider these in the discussion.

\section{Background}

\subsection{Free Speech Controversies on University Campuses}

In the 1980s and 1990s, American universities witnessed lively debates about PC, speech codes, and the restriction of "hate speech", which also caught the attention of the wider public (Lea 2009; Hughes 2010). These debates laid the foundations of divisions that still hold today. Critics of speech codes bemoaned an increasingly repressive intellectual climate on university campuses, the pressure to conform to PC culture, and a growing intolerance toward dissenting views (Bloom 1987; D’Souza 1991). Defenders argued that speech codes protect minority students from discrimination and retaliated by framing the concern with "chilling effects" as mere conservative hysteria (Williams 1995; Wilson 1995).

More recent debates over free speech on university campuses revolve around socalled "trigger warnings," "micro-aggressions," "safe spaces," and "cultural appropriation" (Campbell and Manning 2014; Lukianoff and Haidt 2015; Furedi 2016). Trigger warnings are introductory remarks that warn audiences of potentially distressing contents of a book or lecture. Micro-aggression encompasses speech acts that are intentionally or unintentionally degrading, prejudicial or hostile toward certain (usually minority) groups. The purpose of safe spaces is that disadvantaged groups can come together to discuss their shared experience, protected from criticism and harassment. A majority group commits cultural appropriation if it adopts minority groups' symbols and forms of expressions in decontextualized and exploitative ways.

Controversies about these concepts deal with exactly where to draw the line, the imputation of malevolent intentions, and how to sanction the violation of associated norms. Some argue that these concepts can be interpreted as expressions of a culture of victimhood on university campus, which combines the predisposition to be highly sensitive to offense with the tendency to outsource conflict resolution to authorities 
(Campbell and Manning 2018). This culture is also defined by a conflation of physical and emotional harm and an accentuated identification with minority groups and victim status.

Considerable public attention has also been focused on student protests that have sometimes turned violent, and have led to the disinvitation of "controversial" speakers and the canceling of university events hosting prominent guests owing to security threats. Even university professors have become targets of student-led campaigns for perceived transgressions, which have often resulted in sanctions by university administrations. Some have given in and resigned, others have been suspended or fired.

\subsection{Deplatforming and Canceling at German Universities}

A series of prominent cases in Germany suggests that this trend is not restricted to the English speaking university context. ${ }^{3}$ In 2015 , a group of anonymous social science students at Humboldt-University in Berlin set up a watch blog documenting the allegedly "sexist, racist, and militarist" views of Herfried Münkler, a professor of political theory and well-known public intellectual. In 2016, the university president of the University of Marburg yielded to the pressure of the university's women's affairs officer and uninvited evolutionary biologist Ulrich Kutschera from a lecture series because of his critical views on gender ideology. Again at Humboldt-University in 2016, students protested and publicly accused migration expert and sociology professor Ruud Koopmans of furthering "anti-Muslim racism" and "conceptual nationalism" because of his research on the labor market integration of Muslim immigrants. Later in 2016, a talk by historian Jörg Barberowski organized by a conservative student group was canceled at the University of Bremen. Barberowski, an expert on Stalinism and the history of Eastern Europe who had already been the target of attacks by leftist students in the past, was accused of spreading "right-wing extremist ideology" for his critical views on the German refugee policy.

It is the following two incidents that hit too close to home and that prompted us to research the state of free speech and political viewpoint diversity on university campuses. In fall 2017, a talk by Rainer Wendt, head of the police union, was cancelled at Goethe University in Frankfurt, yielding to the pressure of student groups and an open letter demanding his disinvitation, which was signed by several

\footnotetext{
3 Here, we only report on the most recent cases, but the phenomenon is certainly not new in the German university context. During the student protests of the 1960s and 1970s, for instance, sociologist Erwin K. Scheuch of the University of Cologne was the target of criticism by students for his work on military sociology, which eventually led to a series of court trials (we thank one of the reviewers for bringing this to our attention). Interestingly, Scheuch positioned the empirical-analytical approach to sociology in Cologne in direct opposition to the critical theory of the Frankfurt school. It is perhaps not without irony then, that one of the most famous cases of student attacks at that time involved its key founder, Theodor W. Adorno of Goethe University Frankfurt. In April 1969, in what became known as the "Busenattentat" ("breast attack"), three radical female students surrounded him during the lecture, exposed their breasts, and tried to kiss him. This may have been a feminist statement or simply a reaction to his earlier calling of the police to clear the Institute of Social Research of student protestors. Either way, it turned out to be Adorno's last public lecture before his death a couple of months later.
} 
members of the social science faculty. ${ }^{4}$ Wendt, who had been invited to talk about immigration from the practical perspective of police experience, was criticized for his view on the refugee crisis and accused of furthering "racist modes of thinking." Later, in April 2019, students at Goethe University demanded that ethnographer Susanne Schröter, an expert on Islam, be fired from her position as university professor. Schröter was accused of "anti-Muslim racism" because she organized a critical panel discussion on the Muslim headscarf.

In October 2019, the German public vividly discussed the newest addition to the list. At the University of Hamburg, student activists repeatedly prevented university professor Bernd Lucke from giving his introductory lecture on macroeconomics. As a former founding member of the right-wing party AfD (Alternative for Germany), the students accused Lucke of xenophobia, called him a "Nazi pig" and even physically attacked him.

For some observers, these trends on university campuses are a clear indicator of the dire future of freedom of speech. Others view these incidents as scandalized singular events and regard campus intolerance as a myth. So far, however, both fail to present systematic empirical evidence to support their claims.

\section{What Do We Know Empirically About Free Speech and Intolerance on University Campus?}

\subsection{Evidence from Empirical Research on Political Tolerance}

Surprisingly little is known about the actual state of free speech and political viewpoint diversity on university campuses. Much of the existing evidence can be found in news articles or blogposts and yields mixed results. This is despite the fact that the empirical study of free expression and tolerance has a long tradition in the social sciences, dating back to Stouffer (1955), who studied citizens' willingness to allow nonconformists - in his time and context this meant communists, socialists, and atheists - to publicly speak, teach at universities, and have their books in public libraries (see also Gross and Kinder 1998; Mondak and Sanders 2003; Gibson 1992, 2006, 2013). A key result in this line of research is that people "express strong endorsement of the general principles of free expression and great reluctance to sustain these principles when asked to apply them to noxious groups" (Marcus et al. 1995, p. 8).

Some have used the classical Stouffer method to study the tolerance of university students. Data from the General Social Survey (GSS) 1970-2002, Chong (2006) revealed that US college students were less tolerant of racist speech than the rest of the population, especially the generation educated after the PC debate began, and that this effect was largest for those self-identifying as liberal (in the US sense of the term). He found no evidence, however, for a general climate of intolerance on

\footnotetext{
${ }^{4}$ Both authors were part of the social science faculty at that time. One of us received a considerable negative reaction for publicly criticizing the disinvitation and canceling the event via the faculty mailing list. While many colleagues expressed support for this criticism in private, no-one made it public.
} 
college campuses. Using the same GSS data, but extended to 2016, Sachs (2018) and Yglesias (2018) show that general tolerance of free expression has increased over time and that liberals, the youngest generation, and college students are consistently the most tolerant of all. This is supported by a recent study in the UK that did "not find any evidence that students are more hostile to free speech than the general population" (YouGov 2018).

However, in a series of articles, Stevens and Haidt (2018a, 2018b, 2018c) called the use of GSS data into question. This is because most of the chosen targets of intolerance in these data (e.g., socialists, atheists, homosexuals) are no longer considered controversial, rendering the data inappropriate for longitudinal analyses (echoing the seminal criticism of Sullivan et al. 1979) and virtually meaningless for the study of intolerance among university students, especially those on the left, who are likely to see other targets as objectionable (e.g., racists, sexists, homophobes).

This criticism is supported by studies from social psychology that suggest that although political ideology structures general attitudes toward free speech (e.g., Lalonde et al. 2000; Downs and Cowan 2012; Bilewicz et al. 2017), there is an important interaction between political ideology and content of speech that one wants to see restricted. Suedfeld et al. (1994) suggest that liberals are more likely to support the censorship of racist, sexist, and homophobic messages, whereas political conservatives are more likely to support the censorship of pornography and offensive content regarding religious faith and conservative values. Although Fisher et al. (1999) find that support for censorship is generally higher for the political right than for the left, they also document leftist support for politically correct censorship, especially on university campuses. Concern regarding PC is associated with leftist beliefs and ideologies and with less right-wing authoritarianism (Strauts und Blanton 2015).

Once the targets of intolerance are adjusted, a different view of the state of free expression on university campuses emerges. Drawing on newly designed items from the FIRE/YouGov (2017) survey of undergraduate students in the USA and the Cato Institute's (2017) Free Speech and Tolerance Survey, Stevens and Haidt (2018c) found that students on the left are intolerant toward many speakers who are seen to violate their values and more so than their right-leaning peers. Another recent survey discovered that US students tend to value inclusion and diversity more than free expression and that 10\% deem violence and 37\% shouting down an acceptable measure to prevent someone from speaking (Gallup and Knight Foandation 2018).

What students think about free speech and its limits is critical because changing social norms gradually find their way out of academia and into wider society. Students eventually assume occupational roles and responsibilities in private companies, public administrations, and the media, and bring their ideas with them. Student bodies are also often the origin of social movements and social media trends, which have a direct influence on how political issues are framed and talked about in public.

\subsection{Evidence for Conformity Pressures at the University}

The true significance of ideas for limiting free speech may lie in their contribution to a general culture of conformity and the constraints people impose on each other 
(Noelle-Neumann 1974; Gibson 1992, 2006; Loury 1994). PC debates on university campuses, for instance, may have "created a culture in which everyone must think twice before speaking up, lest they face charges of insensitivity, aggression, or worse" (Lukianoff and Haidt 2015). A possible result is self-censorship. In an environment in which one ideological perspective dominates, individuals with divergent or minority views are likely to suppress their opinions to avoid social exclusion (see the classic "spiral of silence" argument by Noelle-Neumann 1974; Matthes et al. 2018). In public debates this is often described as a "chilling effect," where people do not speak openly for fear of negative consequences.

Interestingly, the question whether intolerance does indeed constrain the expression of political views has been only rarely tested (but see Gibson 1992; Classen and Gibson 2019, who provide supporting evidence for this general claim). Regarding students' willingness to discuss controversial subjects, a representative survey of US college students found that over half are reluctant to share their views on at least one of five controversial topics on campus: politics, race, religion, sexuality, and gender (Stiksma 2020). Students were most concerned about other students criticizing their views for being offensive. The study also suggests that conservative students were more reluctant to talk about controversial topics, which is also supported by a previous survey (Gallup and Knight Foundation 2018).

To the best of our knowledge, there are no current surveys among German students that ask questions similar to the ones discussed above. However, a recent survey of German university teachers indicates that $31 \%$ feel restricted in their teaching by PC (Petersen 2020). Interestingly, differences between the humanities (36\%), the legal, economic, and social sciences (33\%), medicine (28\%), and the natural sciences and engineering $(27 \%)$ are not as great as one might expect.

Our study is an initial step toward charting the state of free speech and viewpoint diversity in the German university context. At this stage, we are not concerned with the testing of causal hypotheses, but aim for a descriptive exploration. How easily offended are students and how tolerant are they of controversial viewpoints? Is there evidence for conformity pressure and does it restrict discussion on university campus? Are students left-of-center more sensitive and more prone to restricted speech? Are their peers right-of-center more reluctant to speak openly? To address these questions, we now turn to our own survey data of social science students at Goethe University Frankfurt.

\section{Data and Methods}

\subsection{The Sample}

The target population of our study are all current social science students at Goethe University of Frankfurt. According to the university's most recent student statistics (Göhring and Götz 2018), a total of $n=6,674$ students were enrolled in one of the social science programs in 2017/2018. We sent out an online questionnaire constructed using the survey software Qualtrics to all students in the department. Participation was voluntary and incentivized with a lottery of three Amazon gift 
vouchers to the value of $€ 50$ each. We were able to collect a total of $n=932$ responses in the period from 16 May to 2 July 2018. However, the actual net response rate dropped from $14 \%$ to $7.5 \%$ when we consider only those who completed at least $80 \%$ of the survey $(n=501)$, which is clearly poor and has to be kept in mind when drawing conclusions from the data. All analyses are based on pair-wise deletion of missing values.

To get a sense of the representativeness of the survey, we compared the composition of our sample with official university statistics (see Table 5 in the appendix). Of the student population, $54.7 \%$ were female and $45.3 \%$ male. This is very close to our sample, where $54.1 \%$ identified as female and $42.2 \%$ as male. We should note that the missing percentage comprised students who identified as "other" gender or who preferred not to say. The sample included more first-year students $(32.7 \%)$ than the true student body $(25.8 \%)$. The distribution across the two main study programs at the department was again well captured by our data (compare 36.2-33.5\% for political science and $43.3-40.6 \%$ for sociology). The remaining percentage referred to students in either one of the specialized master's programs or in the teacher's track. The sample also matched well the gender distribution and first-year students within political science and sociology, with only male sociology students slightly underrepresented by -4.3 percentage points.

Although our sample represented the social sciences studentship at Frankfurt well in terms of key demographics, a graver concern was sample selectivity based on political motivation. In the introduction to the survey we stated that "the purpose of this research study is to examine if and how students think free speech should be regulated within the university and beyond." Given the public controversy, it is unlikely that only students on one side of the debate were more or less likely to participate. However, highly politicized students on the left in particular may have seen quantitative surveys as "instruments of surveillance and control" and actively boycotted participation, thus distorting our sample. Unfortunately, the official student survey conducted by Goethe University in 2017/2018 did not include political variables that would have allowed us to evaluate our sample and to correct it by applying survey weighting. However, if the above-mentioned assumption is true (and we think that it is quite plausible), we would expect this to have worked against our main finding and indeed underestimated campus intolerance.

\subsection{Outcome Variables}

We structure the empirical analysis along several outcome measures tapping into students' experiences with and attitudes toward free expression on university campus. We start our analysis by establishing students' sensitivity to potentially offensive acts of speech or viewpoints. We asked students the following question: "Have you ever felt offended or intimidated by a statement that another person made on campus?"5 Although using this question did not allow us to separate students' sensitivities from actual incidences it gave us a sense of the subjective experiences students made on

\footnotetext{
5 The wording of this question was taken from the Campus Expression Survey (Stevens et al. 2017).
} 
university campus. One in three students or $35 \%(n=165)$ of our sample answered affirmatively to the question.

Next, we adapted Stouffer's (1955) method to elicit tolerance toward viewpoints that focus on controversial ideas about gender equality, sexual identity, immigration, and Islam. Thus, it should be stressed that these measures did not capture tolerance in general (see the classical critique by Sullivan et al. 1979) but only concerning these very specific targets. However, these targets are central in current free speech on university campuses because arguments in favor of restricting speech have for the most part focused on expressions involving minorities and historically disadvantaged groups (Gross and Kinder 1998). We return to this point in the discussion.

The four targets were described as follows: "Somebody who thinks that there are biological differences in talents between men and women," "A person who is against all forms of immigration to this country," "A person who believes that Islam is incompatible with the Western way of life," and finally "A person who thinks that homosexuality is immoral and dangerous." For each target we asked whether they "should be allowed to speak at the university," whether they "should be allowed to teach at the university," and whether students favored "removing their book from the university library." We present the descriptive responses to these questions in Fig. 1 and discuss them in detail further below.

To gauge whether there was indeed evidence for the pressure to conform or the reluctance to speak openly at the university, we looked at three measures: the reluctance to speak openly about controversial political issues during a class discussion, concern over the consequences when speaking up about a controversial political issue, and whether students had ever been personally criticized for their view on a controversial political issue. ${ }^{6}$

The first survey question read: "Next, we are interested in how you would feel about expressing your personal opinions in class discussions at your university. Think of a class with about 20-30 students. Consider the following scenario. Think about being at your university in a class that was discussing a controversial political issue. How comfortable or reluctant would you feel about speaking up and giving your views on this topic?" Students could answer on a four-point scale. Our data suggest that a clear majority of two-thirds of students would feel "somewhat" (42\%) or "entirely" comfortable (24\%) discussing controversial topics in class. However, one in three students reported that they would be "somewhat" $(24 \%)$ or even "entirely" $(11 \%)$ reluctant to openly express their opinion at the university.

We measured students' concerns with the likely consequences if they gave their view on a controversial issue using a simple additive scale of four items: "The professor would criticize my views as offensive," "Other students would criticize my views as offensive," "Someone would file a complaint claiming that my views violated a campus harassment policy," "Someone would post critical comments about my views on social media." For each item respondents could answer on a five-point scale from 1, "not at all concerned," to 5, "extremely concerned." The additive scale ranged from 0 to 20 with a mean of 9.4 , a standard deviation of 4.4 , and Cronbach's $\alpha$ of 0.81 , suggesting good internal scale consistency.

\footnotetext{
6 The wording of these questions was taken from the Campus Expression Survey (Stevens et al. 2017).
} 
a

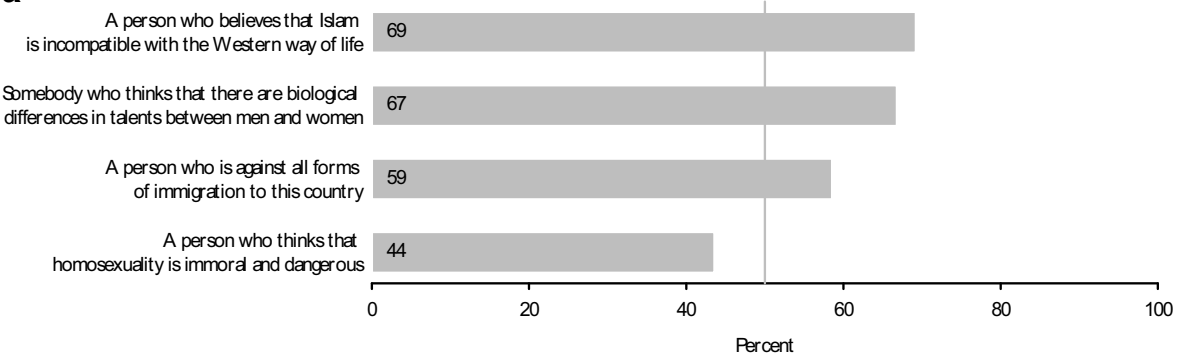

b

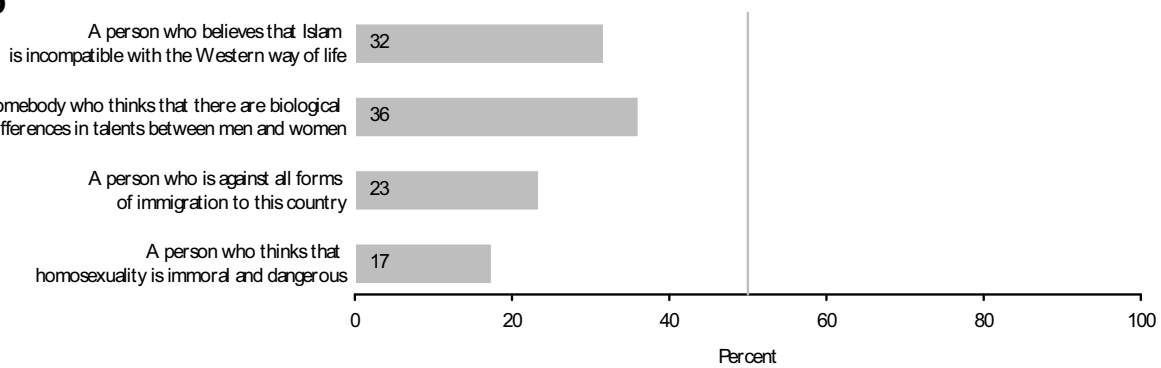

C A person who believes that Islam
is incompatible with the Western way of life

Somebody who thinks that there are biological differences in talents between men and women

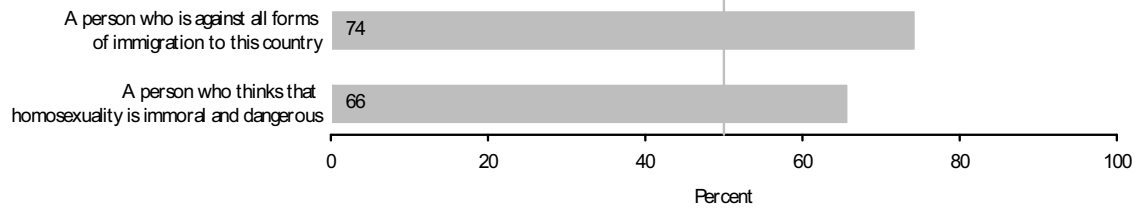

Fig. 1 Description of students' tolerance of controversial topics on university campus. a Should be allowed to speak at the university. b Should be allowed to teach at the university. c Against removing their book from the university library

Last, we asked: "Have you ever felt that your opinion was dismissed or you were personally criticized because you shared your views on a controversial political issue in a class discussion?" Overall, one in four or 25\% $(n=126)$ of the students answered "yes."

\subsection{Predictor Variables}

Given the prominent role of political ideology in debates about free speech on university campus we considered students' political orientation to be a key predictor of their views and experiences. We first directly asked the students how they identify politically. Six percent or $n=28$ students preferred not to say. Among the remainder, 
$51 \%$ identified as "left-wing" $(n=245)$ and $24 \%$ as "liberal" $(n=118)$. Only $4 \%$ stated that they see themselves as "conservative" $(n=18)$ and "libertarian" $(n=17)$ respectively. One percent identified as "right-wing" $(n=4)$ and 11 students as "other" $(n=53)$. Next, we measured the ideological self-placement using the standard 11point left-right scale. The median value of the left-right-scale (which runs from 0 to 10) was 3. Finally, we also asked students which party they had voted for in the 2017 federal election. Although 7\% $(n=35)$ preferred not to say, another 6\% $(n=27)$ had not been eligible to vote and $4 \%(n=18)$ had not turned out to vote. Among the students who had voted, 38\% voted for Die Linke $(n=152), 24 \%$ for Grüne $(n=98), 16 \%$ for SPD $(n=63), 8 \%$ each for CDU/CSU and FDP $(n=33$ and 31 , respectively), and $2 \%$ for the $\operatorname{AfD}(n=9)$. Five percent or $n=19$ students voted for another party. Thus, taken together, three-quarters of the students $(78 \%)$ voted for a left-of-center party. As all three measures yielded essentially the same results and in order to save space, we only report the results for the standard left-right ideology scale in the regression tables below. ${ }^{7}$ We standardized the left-right ideology scale dividing by two standard deviations to make it roughly comparable with the dummy variables in the models (Gelman 2008). Because of the heavy skew and to ensure a minimum of responses on both sides of the ideological spectrum, we decided to code the neutral scale midpoint of 5 as "right-of-center" whenever we conduct categorical comparisons. Thus, students with scores 0-4 were considered "left-ofcenter" and students with scores 5-10 "right-of-center."

We included several additional variables in our analyses. We created a dummy variable for students who were born after 1995. A central claim in the current debate about the free speech crisis on university campus is that younger age cohorts have a distinct and restrictive opinion on free speech. This has partly to do with a change in parenting styles and digital social media, which have made them overly sensitive and emotionally fragile. As a result, they are more likely to feel offended and to demand measures such as speech codes, trigger warnings, or safe spaces (Lukianoff and Haidt 2018; Stevens and Haidt 2018a, 2018b). Relatedly, we constructed another dummy variable for students who began their university education before 2015. This year marked a key transition when important concepts and arguments for restricting what students should be allowed to say or even wear (e.g., "microaggressions", "cultural appropriation", etc.) were widely popularized on university campuses (Stevens and Haidt 2018a, 2018b). We reasoned that students who had been socialized earlier would be less likely to adopt these ideas and thus be more tolerant than students who started their socialization with these concepts already in place (Chong 2006). Finally, we included categorical variables for students' gender and ethnic minority status. As debates about restricting speech on campus were intimately related to questions of equal treatment and non-discrimination, we were interested in any differences along these identity variables. Twenty percent $(n=96)$ of the students in our sample identify as belonging to an ethnic minority (3\% or $n=16$ students preferred not to say). ${ }^{8}$

\footnotetext{
7 Full results of political identification and vote choice are available upon request.

8 We also asked for students' sexual orientation; however, as only $3 \%(N=16)$ identified as homosexual we decided against including sexual minority status in our models.
} 


\subsection{Open Questions and Focus Groups}

We also included two open questions in the survey for a more detailed understanding of the content of students' experience with offensive statements and conformity pressures. If students reported that they had experienced offensive or intimidating statements on university campus, we asked them: "Do you remember the gist of the statement that offended or intimidated you? If so, can you please provide a brief summary of the statement and who made it, using the space below?" If students indicated that they were dismissed because of their political view, we followed up by asking: "Do you remember the gist of the statement you made? If so, can you please provide a brief summary of the statement you made, using the space below?"

Responses to these open questions were coded in terms of the political-ideological thrust of the (perceived and committed) "offense." Based on a classification of statements typically associated with left-leaning or right-leaning political positions, we distinguished two directions of offense: "offensive to the right" and "offensive to the left." Both authors coded all examples of respondents' experiences with offensive statements and being personally dismissed for their views on campus and reached a satisfactory degree of intercoder reliability. Cohen's Kappa was 0.80 for left offenses and 0.79 for right offenses, which suggested strong agreement.

At the end of the survey we asked students if they were interested in participating in a focus group. Two focus group interviews with four participants in each were conducted on 11 July 2018. Because of the small sample, these interviews were not subjected to a systematic analysis but instead were used to support the interpretation of survey results and to illustrate points made in this paper.

\section{Results}

\subsection{Who is Offended by What on University Campus?}

One-third of the students in our sample reported having encountered offensive statements on university campus. Model 1 in Table 1 presents linear probability models that relate students' experience with offensive statements to their individual characteristics. Although ideological self-placement and voting for a leftist party is not associated with experiencing offensive statements, students who identified as "leftwing" tend to be more sensitive to speech on campus and have a $9 \%$ higher probability of reporting an experience $(\beta=0.09, S E=0.04$, not shown in Table 1$)$. We also found that students who had already been enrolled in the university before 2015 were more likely to have encountered offensive or intimidating comments, which may have been due to the simple fact that they had already spent more time

\footnotetext{
9 Some examples, especially those that involved two or more political topics, could not be clearly politically assigned in the German context. A frequent example of this were statements about anti-Semitism in combination with the conflict between Israel and the Palestinians: "A student gave a public speech about the conflict between Israel and Palestine. In his speech he used anti-Semitic language which was far [beyond of] just a critical statement against the political agenda of the Israeli state."
} 
Table 1 Regression Models of Offense Taking and Tolerance on University Campus

\begin{tabular}{lll}
\hline & $\begin{array}{l}(\mathrm{M} 1) \\
\text { Feeling offended or intimidated } \\
\text { by a statement on campus }\end{array}$ & $\begin{array}{l}\text { (M2) } \\
\text { Tolerance of controversial } \\
\text { viewpoints }\end{array}$ \\
\hline Left-right ideology & -0.07 & $2.56^{* * * *}$ \\
& $(0.05)$ & $(0.29)$ \\
Born after 1995 & -0.02 & $-0.70^{* *}$ \\
& $(0.05)$ & $(0.30)$ \\
Studied before 2017 & $0.17^{* * *}$ & $0.83^{* *}$ \\
& $(0.05)$ & $(0.34)$ \\
Male gender & $-0.11^{* *}$ & $2.07^{* * *}$ \\
& $(0.05)$ & $(0.29)$ \\
Other gender & 0.24 & 1.60 \\
& $(0.17)$ & $(1.21)$ \\
Prefer not to specify & 0.17 & 1.37 \\
gender & $(0.21)$ & $(1.29)$ \\
Ethnic minority & 0.05 & -0.28 \\
Prefer not to specify & $(0.06)$ & $(0.36)$ \\
ethnicity & 0.21 & -0.47 \\
Constant & $(0.15)$ & $(0.91)$ \\
$n$ & $0.33^{* * *}$ & $5.81^{* * *}$ \\
$\mathrm{R}^{2}$ & $(0.05)$ & $(0.30)$ \\
\hline
\end{tabular}

M1 Linear Probability Model, M2 Ordinary Least Squares Model ${ }^{*} p<0.1 ;{ }^{* *} p<0.05 ;{ }^{* * *} p<0.01$

on campus $(\beta=0.17, S E=0.05)$. Male students are generally less likely to feel offended or intimated by comments and remarks $(\beta=-0.11, S E=0.05)$. Interestingly, neither younger age cohorts nor students with an ethnic minority background stood out regarding experiences with offensive statements.

To get a better sense of the content of the speech that students found troubling, we asked them to describe their experience in an open question (see Table 2). Although respondents right-of-center provided only a few examples, the vast majority of responses $(75 \%)$ came from left-leaning students being offended by statements they deemed as too conservative, as violating, or insufficiently adhering to speech norms. This is, of course, mainly due to the skewed distribution of political ideology in the sample. By far the most prominent subjects of scenarios were gender and sexuality (half of all responses). The few students right of center were offended by students and lecturers arguing that gender is merely a social construct, whereas students left of center were offended by the opposite argument: "Elderly male professor denying any social influence in gender creation. It is all biological, he said," to give an example. Left-leaning students were further offended by homophobic, misogynist, sexist comments, and 'mansplaining.' Many responses did not describe specific scenarios but were general, as in: "sexist comments by fellow students and professors." There was some overlap between male students on both sides of the political spectrum taking offense with regard to feeling dismissed as men. 
Table 2 Students' experience with offensive statements on university campus by direction of offense and students' political ideology

\begin{tabular}{|c|c|c|}
\hline & Student left-of-center & Student right-of-center \\
\hline $\begin{array}{l}\text { Offensive } \\
\text { to the } \\
\text { Left }\end{array}$ & $\begin{array}{l}72 \%(n=55) \\
\text { "When a prof said he is able to prove } \\
\text { philosophically that women cannot think." } \\
\text { "Students claiming that Muslims are not } \\
\text { compatible with the Western culture be- } \\
\text { cause of their different values. 'Muslims } \\
\text { are too aggressive and violent,' etc." } \\
\text { "In another class the topic was reproduc- } \\
\text { tive rights and a female student argued } \\
\text { against free access to the (contraceptive) } \\
\text { morning-after pill by equating it with abor- } \\
\text { tion." } \\
\text { "All people reading Marx would be Com- } \\
\text { munists, or did not understand how eco- } \\
\text { nomics really work in our society." }\end{array}$ & $\begin{array}{l}4 \%(n=3) \\
\text { "In a discussion about the Trump election } \\
\text { someone tried to play down Trump's 'grab } \\
\text { them by the pussy statement' as normal } \\
\text { behavior for men" } \\
\text { "Someone said that all overweight persons } \\
\text { are just lazy, inconsequent, unable to set } \\
\text { and reach goals. It was not possible to dis- } \\
\text { cuss with this person and the real problem } \\
\text { was, that this person was not able to accept } \\
\text { a different view and became very insulting } \\
\text { (no objective discussion was possible)" } \\
\text { "A student said that all people who suffer } \\
\text { from mental illnesses and/or depression are } \\
\text { weak and unbearable." }\end{array}$ \\
\hline $\begin{array}{l}\text { Offensive } \\
\text { to the } \\
\text { Right }\end{array}$ & $\begin{array}{l}12 \%(n=9) \\
\text { "The statement was about me being a dick } \\
\text { because I was white, male, and hetero- } \\
\text { sexual (therefore I logically must be an } \\
\text { asshole)" } \\
\text { "A fellow student in a seminar compared } \\
\text { consuming animal products to the holo- } \\
\text { caust." } \\
\text { "I dislike it if people are calling for vio- } \\
\text { lence or vandalism to push through polit- } \\
\text { ical agendas. It regularly happens during } \\
\text { campus (AStA) election campaigns and } \\
\text { frequently in private discussions, some- } \\
\text { times even in classes and lectures." }\end{array}$ & $\begin{array}{l}12 \%(n=9) \\
\text { "A female professor frequently made pub- } \\
\text { lic comments in a big class about how bad } \\
\text { men generally are." } \\
\text { "When I criticized social media restrictions } \\
\text { in Germany due to the 'Netzwerkdurch- } \\
\text { setzungsgesetz', the Professor said that } \\
\text { I would not understand what hate speech } \\
\text { is. I asked her to define hate speech. She } \\
\text { got angry, pointed her finger at me and } \\
\text { said: 'I know what to think about your } \\
\text { views now.", } \\
\text { "That gender is made up and conservatives } \\
\text { are racist." }\end{array}$ \\
\hline
\end{tabular}

\subsection{Are Students Really Intolerant of Controversial Views on University Campus?}

In this section we explore whether and how students' sensitivities translate into intolerance and the restriction of controversial topics on university campuses. Figure 1 presents the descriptive responses to these questions. Overall, majorities of between 60 and $80 \%$ of the students think that controversial speakers should be able to speak at the university and that books with controversial content should be available at the university library. Although this seems to indicate comfortable levels of tolerance, it also means that $20-40 \%$ favored the restriction of free expression. In addition, clear majorities also stated that persons who hold controversial views should not be allowed to teach at the university. In more detail, only $69 \%$ would allow a speaker who is critical of Islam on campus (78\% would allow their book in the library), $67 \%$ a speaker who thinks that there are biological skills differences between the men and women (81\% would allow their book in the library), and 59\% someone who is opposed to immigration ( $74 \%$ would allow their book in the library). Only $44 \%$ of the students would tolerate a speaker who thinks that homosexuality is a sin and $66 \%$ would have their book in the university library. 
When it comes to the question who should be allowed to teach at the university, only a third of the students thought that this should be the case for someone who believes in biological differences in talents between the sexes $(36 \%)$ or who views Islam as incompatible with Western society (32\%). Only a quarter of the students would accept a university teacher who is strictly opposed to immigration (23\%) and even fewer a person who believes that homosexuality is immoral (17\%). Our focus group conversations with students suggested that a common motivation behind this attitude was that students feared that university teachers would not be able to separate their opinion from their professional role as supervisors. In other words, the concern was that female, Muslim, immigrant, or homosexual students or students who were to take their sides might have been treated unfairly.

\subsection{Are Left-Leaning Students Really More Willing to Restrict Free Speech on University Campus?}

To analyze ideological differences in intolerance toward controversial speakers on university campus, we added up all the items to construct a simple tolerance of nonconformism scale that runs from 0 to 12 (with a mean of 6.5 , a standard deviation of 3.3, and a Cronbach's $\alpha$ of 0.85). Model 2 in Table 1 presents the results of an ordinary least squares (OLS) regression of the tolerance score on the left-right self-placement, along with indicators of whether students were born after 1995, whether they had studied before 2015 as well as their gender and ethnic minority status. We did indeed find that the left-right ideology was clearly and significantly related to preferences for restricting free expression on campus $(\beta=2.56, S E=$ 0.29 ). Right-leaning students were more tolerant of controversial opinions about gender, homosexuality, immigration, and Islam than their left-leaning counterparts. Additional analyses not shown here suggested that students who explicitly selfidentified as left wing were significantly less tolerant of controversial views and speakers $(\beta=-2.23, S E=0.29)$. Students who voted for Die Linke, Grüne, or SPD were also significantly less tolerant of controversial ideas on university campuses $(\beta=-1.28, S E=0.32)$. In addition, we found that students born after 1995 and students who started in 2015 or later were less tolerant, whereas male students were more tolerant of these ideas than female students. Ethnic minority status was not related to preferences for speech regulation.

\subsection{Are Students Really Reluctant to Speak Openly at the University?}

One-third of our students reported that they would be at least "somewhat" reluctant to openly express their political opinion during a class discussion. Model 1 in Table 3 shows the result of regressing students' reluctance to openly give their political views on their individual characteristics. ${ }^{10} \mathrm{We}$ found that right-leaning students were significantly more likely to withhold their political views during class discussions $(\beta=0.29, S E=0.09)$. Conversely, students who self-identified as politically left-

\footnotetext{
10 For the sake of simplicity and ease of interpretation, we ran OLS models instead of Ordered Logit or Ordered Probit models. The substantive interpretation is unlikely to be affected.
} 
Table 3 Regression Models of Conformity Pressures and Self-Censorship on University Campus

\begin{tabular}{llll}
\hline & $(\mathrm{M} 1)$ & $(\mathrm{M} 2)$ & $(\mathrm{M} 3)$ \\
& $\begin{array}{l}\text { Reluctance to speak } \\
\text { political views openly in } \\
\text { class }\end{array}$ & $\begin{array}{l}\text { Concern regarding con- } \\
\text { sequences of political } \\
\text { views }\end{array}$ & $\begin{array}{l}\text { Experience of being } \\
\text { dismissed for political } \\
\text { views }\end{array}$ \\
\hline $\begin{array}{l}\text { Left-right } \\
\text { ideology }\end{array}$ & $0.29^{* * *}$ & $2.10^{* * *}$ & $0.15^{* * *}$ \\
Born after & $(0.09)$ & $(0.42)$ & $(0.04)$ \\
1995 & 0.03 & 0.03 & -0.02 \\
Studied before & $(0.09)$ & $(0.44)$ & $(0.04)$ \\
2015 & -0.00 & -0.77 & 0.01 \\
Male gender & $(0.10)$ & $(0.49)$ & $(0.05)$ \\
& $-0.32^{* * *}$ & $-0.95^{* *}$ & $0.09^{* *}$ \\
Other gender & $(0.09)$ & $(0.42)$ & $(0.04)$ \\
Prefer not to & 0.06 & 0.42 & 0.25 \\
specify gender & $(0.33)$ & $(1.56)$ & $(0.16)$ \\
Ethnic minor- & 0.06 & 0.45 & -0.10 \\
ity & $(0.11)$ & $(1.88)$ & $(0.19)$ \\
Prefer not & 0.16 & 0.15 & $0.12^{* *}$ \\
to specify & $(0.27)$ & $(0.53)$ & $(0.05)$ \\
ethnicity & & $2.84^{* *}$ & 0.20 \\
Constant & $2.32^{* * *}$ & $(1.28)$ & $(0.13)$ \\
Observations & $(0.09)$ & & $0.20^{* * *}$ \\
$\mathrm{R}^{2}$ & 454 & $9.93^{* * *}$ & $(0.04)$ \\
\hline
\end{tabular}

M1 \& M2 Ordinary Least Squares Model, M3 Linear Probability Model ${ }^{*} p<0.1 ;{ }^{* *} p<0.05 ;{ }^{* * *} p<0.01$

wing were generally more comfortable about speaking up on controversial political issues $(\beta=-0.32, S E=0.09)$. The same held for students who had voted for Die Linke, Grüne, or SPD in the last election ( $\beta=-0.27, S E=0.09)$. Apart from political ideology, male students were generally more comfortable about giving their view than female students. We found differences across neither student age cohorts nor ethnic identities.

Model 2 in Table 4 presents the results of an OLS regression that regresses students' concern regarding the consequences if they were to give their political view on their characteristics. Right-leaning students were significantly more concerned that giving their political views would result in disapproval ( $\beta=2.10, S E=0.42$ ). Those who explicitly identified as "left wing" were significantly less likely to feel concerned $(\beta=-1.89, S E=0.41)$ as were the students who voted for a leftof-center party $(\beta=-0.98, S E=0.44)$. In addition, we found that males were less worried about consequences when giving their political views in the classroom. Those students who did not want to disclose their ethnic identity were significantly more concerned about the potential consequences.

One quarter of the students had experienced criticism for their political views. Model 3 in Table 4 shows differences across student characteristics. Students who were further toward the right than average had a significant and 15\% higher prob- 
Table 4 Students' Experience of Being Dismissed or Criticized for Their Views in Class Discussion by Direction of Offense and Students' Political Ideology

\begin{tabular}{|c|c|c|}
\hline & Student Left-of-center & Student Right-of-center \\
\hline $\begin{array}{l}\text { Offensive } \\
\text { to the } \\
\text { Left }\end{array}$ & $\begin{array}{l}38 \%(n=23) \\
\text { "We talked about the custom in a Latin- } \\
\text { American country to bury [unplanned] } \\
\text { children alive. My opinion is, that this } \\
\text { should be prohibited, because human rights } \\
\text { are more worth than customs ... My fellow } \\
\text { students started arguing and offending me } \\
\text { with the Eurocentric argument 'People } \\
\text { from the western world can't force others } \\
\text { to do what they think is right."” } \\
\text { "I once argued that unions were bad for the } \\
\text { unemployed and nowadays also rather bad } \\
\text { for economic growth and therefore should } \\
\text { enjoy fewer rights and privileges than they } \\
\text { do in France today." } \\
\text { "I said that honor killings happen in Ger- } \\
\text { many." }\end{array}$ & $\begin{array}{l}37 \%(n=22) \\
\text { "I made the point that an institution in } \\
\text { itself is not discriminating against some } \\
\text { groups but rather individuals in the in- } \\
\text { stitution that set up rules that might be } \\
\text { discriminating or make decisions that are } \\
\text { discriminating ... Prof and some students } \\
\text { insisted on it without tackling my con- } \\
\text { cerns. They were very satisfied when I did } \\
\text { not want to continue the discussion." } \\
\text { "While discussing the last American elec- } \\
\text { tion in class I made the statement that } \\
\text { freedom of expression involves all opin- } \\
\text { ions in the political spectrum, which got } \\
\text { dismissed (by the lecturer) because 'some } \\
\text { opinions aren't opinions' ... After asking } \\
\text { what constitutes an opinion in the lecturer's } \\
\text { opinion I was pointed to the long history } \\
\text { of the word. This rhetorical figure, in the } \\
\text { manner it was presented, had the goal of } \\
\text { silencing me." }\end{array}$ \\
\hline $\begin{array}{l}\text { Offensive } \\
\text { to the } \\
\text { Right }\end{array}$ & $\begin{array}{l}23 \%(n=14) \\
\text { "Every kind of immigrant should be al- } \\
\text { lowed to live in this country." } \\
\text { "I said that the border regime of the Euro- } \\
\text { pean Union is responsible for the deaths of } \\
\text { refugees on the Mediterranean Sea." } \\
\text { "I defended the idea that girls/women } \\
\text { wearing a headscarf in Germany were } \\
\text { not always repressed in their opinion and } \\
\text { forced to do so, but might themselves } \\
\text { prefer to wear one." }\end{array}$ & $\begin{array}{l}2 \%(n=1) \\
\text { "I denounced religion." }\end{array}$ \\
\hline
\end{tabular}

ability of having experienced their opinions dismissed in a class discussion. This had happened significantly less often to left-leaning students and students who had voted for left-of-center parties. Males were significantly more likely to be personally criticized for their political opinion than female students as were students with an ethnic minority background.

To learn more about which opinions were dismissed during class discussions, we asked students in an open question to describe what they had said in that situation (see Table 4). Many examples are in line with the findings mentioned above: (conservative) students being dismissed by others for making critical, insensitive or merely empirically qualifying remarks about the discrimination of women, or ethnic or sexual minorities, as well as (to a far lesser extent) arguments critical of immigration. Being labelled as "homophobic," "racist," or "sexist" was often the consequence. This also happened to faculty members. One focus group participant told us that one of her male professors who had refused to use gender-neutral language was immediately labeled as "sexist" by students. She also described a situation in a class discussion where one student made a comment that others took as apologizing for 
a homophobic catchphrase: "He said 'I just meant it as a joke. I'm not homophobic' and then everybody ganged up on him and said 'How can you? What an intolerant opinion!' No matter what my position is in this matter; I also don't think it is ok to say that, but yet he wasn't taken seriously. He was immediately portrayed as a homophobic person somehow" (female student, 27).

What was remarkable, furthermore, was that even statements of left-leaning students were subject to speech policing on the part of (presumably even more leftleaning) students. To illustrate, compare the following two examples: "I said that feminism can be a kind of extremism if it's going too far" and "I claimed, that left extremism is as bad as right extremism or Islamism, because all these three want to violate the life and health of people." The first scenario involved a student who classified herself as left-wing (with a score of 2 on the left-right scale and who voted for Die Linke in the last federal election), the second a conservative male student (with a score of 7 and who voted for CDU/CSU). Both believed, however, that most of their fellow students were more leftist than them.

Other left-leaning students were reprimanded for using the word Rasse (race) or for arguing that immigrants should be deported if they were denied asylum and their home country was not at war. A female student left-of-center provoked her fellow students when she spoke out against gender quotas in companies and a male student left-of-center "got aggressively approached by a female person sitting next to me for saying that I liked the egalitarian use of gender-specific speech where sometimes the author uses a male and a female version of a word." She accused him of "violating women's rights" by not using the "*' convention of gender-neutral language. ${ }^{11}$

Students on both sides of the ideological spectrum were also dismissed for their views on free speech itself. One right-of-center student (left-right score 6, FDP voter) argued in a discussion on the 2016 US presidential election that freedom of expression included all political opinions. The lecturer rebuked this statement by saying that "some opinions aren't opinions." When the student asked the lecturer what constituted an opinion in his opinion, a historical exegesis of the term followed. Instead of enhancing his understanding, the student felt that "this rhetorical figure, in the manner it was presented, had the goal of silencing me." Although most of the situations described involved students' opinions dismissed by other students, there were several instances in which professors and lecturers restricted speech. This also came up frequently in our focus groups. As one participant (female, 27) told us, "I have one lecturer who, I would say, is on one political side and ... there are restrictions in what you can say. Because the boss in the room has a very clear opinion."

Students were not only criticized for violating or not adhering to speech norms but also for overly demanding conformism and making arguments that were too progressive, although to a lesser extent (less than one-third of responses). These statements were in favor of abortion, on admitting European guilt regarding the

\footnotetext{
${ }^{11}$ One such convention in the German language is to insert an asterisk before or after gender-specific syllables and adding—e.g. "Student*in" (student)—or highlighting—e.g., "Beamte*r" (civil servant)—the female suffix to signify inclusiveness of both genders as well as nonbinary people. We should note, however, that this form of "gender-inclusive" language is itself controversial.
} 
situation in African countries and regarding refugee deaths in the Mediterranean Sea, against an overly punitive penal system and for condemning statements as racist. One female student was dismissed for arguing that it was cultural appropriation when white people wear dreadlocks without reflecting on their historical meaning. Coincidentally, another left-leaning male student in the survey felt dismissed for making the opposite argument against the inflationary use of the term "cultural appropriation" in a discussion about dreadlocks (possibly in the same debate).

\section{Discussion and Conclusion}

Our study has shed some light on the state of free speech and political viewpoint diversity on university campuses by focusing on a most likely case for PC culture: social science students at Goethe University of Frankfurt. Our reasoning was simple: if we cannot find evidence for a restrictive ideological discussion climate and social pressures to conform here, we would be unlikely to find these tendencies in other places. We would then be safe to declare the new campus intolerance a mere myth.

Our preliminary results contradicted this optimism and may be succinctly summarized in three main points. First, while taking offense and feeling intimidated by statements made on campus is a common experience of one-third of all students, a clear majority were tolerant of different, even controversial viewpoints. But this should not hide the fact that a considerable number of students were in favor of restricting speech. Depending on the controversial topic, between 30\% ("Islam is incompatible with the West") and 54\% ("homosexuality is immoral") of the students would not allow a speaker to speak on campus. And even higher shares, ranging from $64 \%$ ("there are biological differences in talents between men and women") to $83 \%$ ("homosexuality is immoral"), thought that individuals holding such views should not be allowed to teach at the university. Roughly one-third of students would also favor the banning of these individuals' books from the university library.

Second, one-quarter of all students had experienced personal dismissal for voicing their opinion and one-third felt at least somewhat inhibited about giving their view on controversial issues in a class discussion. Thus, our findings resonate with wellknown theories of public opinion (such as the spiral of silence by Noelle-Neumann 1974) in that students chose to remain silent out of fear of being socially isolated and stigmatized. Our findings further suggest that students might have been concerned with the reactions of both fellow students and professors, although slightly less for the latter. Although $31 \%$ were "moderately" or "extremely" concerned that other students would criticize their views as being offensive, only $20 \%$ feared that their professors would criticize them for their views.

Third, both the intolerance of controversial views and the reluctance to speak openly on university campuses were clearly structured along students' political ideology. Students who placed themselves at the left of the ideological spectrum were significantly less likely to tolerate controversial speakers, teachers, or books at the university. Feeling pressure to conform was especially true for right-of-center students who, in the face of an overwhelming majority of left-leaning opinions, were reluctant to speak their mind on politically sensitive issues, such as gender, sexuality, 
and immigration. But even students who mostly sided with majority opinions were cautious and/or had experienced a negative reaction for speaking out about such issues.

Given that the impetus for proponents of campus speech codes and the restriction of hate speech stems from their desire to fight discrimination and to foster an inclusive learning environment, it is instructive to summarize our findings from a gendered perspective as well as from the perspective of ethnic minority students. We found that the issue of free speech and conformity was significantly structured by students' gender. Indeed, gender rivaled political ideology in terms of its effect sizes. Male students were significantly less likely to feel offended, more tolerant of controversial speech (in accordance with Downs und Cowan 2012), more likely to openly give their opinion and also less likely to be concerned with the consequences of their statements. At the same time, however, they were significantly more likely to experience personal dismissal or criticism for their views.

Let us contrast this with the experiences and attitudes of university students with ethnic minority status. Students with an ethnic minority background did not differ from majority background students in any of the measures of sensitivity, tolerance (supporting the findings in Chong 2006), or conformity pressures that we have considered in this analysis. Maybe ironically, the only exception to this pattern was experiencing personal criticism for their political views. Ethnic minority students were significantly more likely to report that they were dismissed for their political views, and this difference was comparable in size with the difference based on political ideology.

Several points of qualification of our analysis are in order. First, we are well aware that our data have limitations. One was the low response rate of our student survey, which cautioned us to be modest in our claims. In addition, owing to the cross-sectional nature of our survey data we were only able to present a snapshot of the current climate on the university campus. We therefore cannot say whether the current situation is new or whether it has become worse over the recent years. Even more importantly, we cannot say much about the prevalence of intolerance and ideological pressures to conform at other departments at Frankfurt University (e.g., economics, law, or the natural sciences) or how our findings generalize across other university contexts in Germany. Yet, to appreciate our contribution one has to bear in mind that, so far, the German discussion has been based on no data at all. We view our evidence as suggestive and meriting further study in alternative contexts and at future time points.

Second, one could argue that our measure of tolerance for controversial topics is unfairly stacked against sensitivities of the left (i.e., by referring to gender equality, sexual minorities, Islam, and immigration). Although this choice of controversial topics was driven by the actual content of current debates over free speech on campus, it would be interesting to test some hot-button issues on the right (e.g., abortion, calls to violence against the police, or the abolition of the nation state). Research on US students, which used a broader range of tolerance items, suggests that students on the right are indeed more tolerant toward guest speakers with, in their mind, objectionable views, than students on the left (Stevens and Haidt 2018c). 
As a first step toward a more ideologically balanced assessment of intolerance we also replicated the Pew Freedom of Expression Scale (Wike and Simmons 2015) in our student sample. This scale asks whether people should be able to say certain things publicly or whether the government should be able to prevent them from speaking freely. Regressing the ideological left-right placement separately on each of the five items, we found no significant ideological differences for statements criticizing the government, statements that are offensive to respondents' religious beliefs, or statements that are sexually explicit-all of which can be regarded as targeting sensitivities of the right (Suedfeld et al. 1994). However, we found that right-leaning students are more willing to allow statements that are offensive to minorities than their left-leaning peers $(\beta=0.12, p=0.01)$. The only instance where students right-of-center are significantly less tolerant than their fellow students leftof-center concerns statements that call for violent protests $(\beta=-0.33, p=0.01)$.

Third, it is important to understand that we are not saying that extreme right-wing views are illegitimately shut down on university campus. Although the acceptance of extremist views on university campus is an important debate in itself, we are concerned with the silencing of legitimate political views that simply deviate from leftist orthodoxy on issues such as gender, immigration, and sexual or ethnic minorities. It is students who place themselves right-of-center, who identify as conservative, classical liberal, libertarian, or who vote for parties such as the CDU or FDP who are reluctant to speak openly about these political issues.

Overall, the empirical tendencies we have uncovered suggest that we cannot simply dismiss concerns about a restrictive discursive climate on university campuses. Instead, we should heed these warning signs and carefully consider their implications. A recent study about conservative students in the USA suggests that being in the political minority on campus might not only entail social isolation but also resilience through "honing one's argument" (Binder and Wood 2013, p. 154). Thus, aside from excluding and silencing dissenting voices, the narrowing of viewpoint diversity may be an even greater problem for students who generally agree with the dominant views: ${ }^{12}$ Failing to learn how to assert one's position argumentatively against objections is ultimately a significant disadvantage at all later stages of life.

Although preliminary, our findings may have more far reaching implications for the social sciences. A lack of viewpoint diversity and pressures to conform are to the clear detriment of teachers, scholars, and researchers, whose thinking would benefit from more challenges in the classroom and among colleagues. We all have biases and blind spots-but if we all share the same ideological lens on critical issues of social scientific interest, we as a field lose our capacity to detect and correct them. Homogenous faculties of politically like-minded students, teachers, and researchers cannot be conducive to sound social science. A lack of viewpoint diversity not only undermines intellectual creativity and scientific rigor but may ultimately also damage the public's trust in the social sciences.

Funding RT acknowledges partial support from the Forschungsinstitut Gesellschaftlicher Zusammenhalt (FGZ)/Research Institute Social Cohesion (RISC) funded by the Federal Ministry of Education and Research (BMBF).

12 This, of course, just echoes what John Stuart Mill (1859) already realized more than a century ago. 
Funding Open access funding provided by University of Leeds.

Open Access This article is licensed under a Creative Commons Attribution 4.0 International License, which permits use, sharing, adaptation, distribution and reproduction in any medium or format, as long as you give appropriate credit to the original author(s) and the source, provide a link to the Creative Commons licence, and indicate if changes were made. The images or other third party material in this article are included in the article's Creative Commons licence, unless indicated otherwise in a credit line to the material. If material is not included in the article's Creative Commons licence and your intended use is not permitted by statutory regulation or exceeds the permitted use, you will need to obtain permission directly from the copyright holder. To view a copy of this licence, visit http://creativecommons.org/licenses/by/4. $0 /$.

\section{Appendix}

Table 5 Comparison of Sample with Official University Statistics

\begin{tabular}{llllll}
\hline & \multicolumn{2}{l}{ Official Statistics } & \multicolumn{2}{l}{ Sample } & \multicolumn{2}{c}{ Difference } \\
& $n$ & $\%$ & $n$ & $\%$ & \\
\hline Total & 6674 & 100 & $-^{\mathrm{a}}$ & $-^{\mathrm{a}}$ & - \\
Total Female & 3653 & 54.7 & 265 & $54.1^{\mathrm{b}}$ & -0.6 \\
Total Male & 3021 & 45.3 & 207 & $42.2^{\mathrm{b}}$ & -3.1 \\
Total First Year & 1724 & 25.8 & 153 & 32.7 & +6.9 \\
Political Science & 2415 & 36.2 & 155 & 33.5 & -2.7 \\
Political Science Female & 1115 & 16.7 & 69 & 14.9 & -1.8 \\
Political Science Male & 1300 & 19.5 & 84 & 18.1 & -1.4 \\
Political Science First Year & 695 & 10.4 & 55 & 11.8 & +1.4 \\
Sociology & 2893 & 43.3 & 188 & 40.6 & -2.7 \\
Sociology Female & 1797 & 26.9 & 121 & 26.1 & -0.8 \\
Sociology Male & 1096 & 16.4 & 56 & 12.1 & -4.3 \\
Sociology First Year & 730 & 10.9 & 61 & 13.1 & +2.2 \\
\hline
\end{tabular}

${ }^{a}$ Number of observations and percentages are based on pair-wise deletion of missing values

bShares of female and male do not add up to 100 because of respondents who reported "other" or "prefer not to say" 


\section{References}

Baer, Ulrich 2019. What Snowflakes Get Right: Free Speech, Truth, and Equality on Campus. New York: Oxford University Press.

Bilewicz, Michal, Wiktor Soral, Marta Marchlewska and Mikołaj Winiewski. 2017. When Authoritarians Confront Prejudice. Differential Effects of SDO and RWA on Support for Hate-Speech Prohibition. Political Psychology 38:87-99.

Binder, Amy J., and Kate Wood. 2013. Becoming right: How campuses shape young conservatives. Princeton: Princeton University Press.

Bloom, Allan. 1987. The closing of the American mind: how higher education has failed democracy and impoverished the souls of today's students. New York: Simon and Schuster.

Campbell, Bradley, and Jason Manning. 2014. Microaggression and moral cultures. Comparative Sociology 13:692-726.

Campbell, Bradley, and Jason Manning. 2018. The rise of victimhood culture: microaggressions, safe spaces, and the new culture wars. New York, NY: Palgrave Macmillan US.

CATO Institute/YouGov. 2017. Cato Institute 2017 Free Speech and Tolerance Survey. https://www. cato.org/sites/cato.org/files/survey-reports/tables/cato-free-speech-survey-tables-and-crosstabs.pdf. Accessed: 10 Oct 2020.

Chong, Dennis. 2006. Free Speech and Multiculturalism In and Out of the Academy. Political Psychology 27:29-54.

Claassen, Cristopher, and James L Gibson. 2019. Does Intolerance Dampen Dissent? Macro-Tolerance and Protest in American Metropolitan Areas. Political Behavior, 41:165-185.

Dow, Erin, and Marc Lendler. 2002. Civil Liberties and the Moderate Thought Police. Political Science \& Politics 35(3):549-553.

Downs, Daniel M., and Gloria Cowan. 2012. Predicting the Importance of Freedom of Speech and the Perceived Harm of Hate Speech. Journal of Applied Social Psychology 42:1353-1375.

D'Souza, Dinesh. 1991. Illiberal Education: The Politics of Race and Sex on Campus. New York: The Free Press.

Etzioni, Amitai. 2014. Don't Sweat the Microaggressions. The Atlantic. https://www.theatlantic.com/ politics/archive/2014/04/dont-sweat-the-microaggressions/360278/. Accessed 18 June 2018.

Feldstein, Richard. 1997. Political correctness: a response from the cultural Left. Minneapolis: University of Minnisota Press.

FIRE/YouGov. 2017. Speaking Freely: What Students Think about Expression at American Colleges. https://d28htnjz2elwuj.cloudfront.net/wp-content/uploads/2017/10/11091747/survey-2017-speakingfreely.pdf. Accessed: 10 Oct 2020.

Fisher, Randy, Stuart Lilie, Clarice Evans, Greg Hollon, Mary Sands, Dawn Depaul, Christine Brady, David Lindbom, Dawn Judd, Michelle Miller, and Tim Hultgren. 1999. Political Ideologies and Support for Censorship: Is It a Question of Whose Ox Is Being Gored? Journal of Applied Social Psychology 29:1705-1731.

Furedi, Frank. 2016. What's Happened to the University? A Sociological Exploration of its Infantilisation. Routledge.

Gallup and Knight Foandation. 2018. Free expression on campus: What college students think about first amendment issues. https://knightfoundation.org/wp-content/uploads/2020/01/Knight_Foundation_ Free_Expression_on_Campus_2017.pdf. Accessed 10 Oct 2020

Gelman, Andrew. 2008. Scaling regression inputs by dividing by two standard deviations. Statistics in Medicine 27:2865-2873.

George, Alexander, and Andrew Bennett. 2005. Case Studies and Theory Development in the Social Sciences. MIT Press.

Gerring, John. 2007. Is There a (Viable) Crucial-Case Method? Comparative Political Studies 40(3): 231-253.

Gibson, James L. 1992. The political consequences of intolerance: Cultural conformity and political freedom. American Political Science Review 86 (2):338-356.

Gibson, James L. 2006. Enigmas of Intolerance: Fifty Years after Stouffer's Communism, Conformity, and Civil Liberties. Perspectives on Politics 4:21-34.

Gibson, James L. 2013. Measuring political tolerance and general support for pro-civil liberties policies: Notes, evidence, and cautions. Public Opinion Quarterly 77(S1):45-68.

Göhring, Rebekka, und Götz, Christoph. 2018. Studierendenstatistik. Wintersemester 2017/18. Goethe Universität Frankfurt. 
Gross, Kimberly A., and Donald R. Kinder. 1998. A Collision of Principles? Free Expression, Racial Equality and the Prohibition of Racist Speech. British Journal of Political Science 28:445-471.

Hughes, Geoffrey. 2010. Political correctness: a history of semantics and culture. Maldon, Mass: WileyBlackwell.

Lalonde, Richard N., Lara Doan and Lorraine A. Patterson. 2000. Political Correctness Beliefs, Threatened Identities, and Social Attitudes. Group Processes \& Intergroup Relations 3:317-336.

Lea, John. 2009. Political correctness and higher education: British and American perspectives. New York: Routledge.

Lilla, Mark. 2016. The End of Identity Liberalism. The New York Times. https://www.nytimes.com/2016/ 11/20/opinion/sanday/the-end-of-identity-liberalism.html. Accessed 18 June 2018.

Loury, Glenn C. 1994. Self-Censorship in Public Discourse: A Theory of Political Correctness and Related Phenomena. Rationality and Society 6(4):428-461.

Lukianoff, Greg, and Jonathan Haidt. 2015. The Coddling of the American Mind. The Atlantic. https:// www.theatlantic.com/magazine/archive/2015/09/the-coddling-of-the-american-mind/399356/. Accessed 10 Oct 2020 .

Lukianoff, Greg, and Jonathan Haidt. 2018. The Coddling of the American Mind: How Good Intentions and Bad Ideas Are Setting up a Generation for Failure. New York: Penguin Press.

Marcus, George E., John L. Sullivan, Elizabeth Theiss-Morse and Sandra L. Wood. 1995. With malice toward some: How people make civil liberties judgments. Cambridge University Press.

Matthes, Jörg, Johannes Knoll and Christian von Sikorski. 2018. The 'Spiral of Silence' Revisited: A Meta-Analysis on the Relationship Between Perceptions of Opinion Support and Political Opinion Expression. Communication Research 45:3-33.

Mill, John Stuart. 1859. On liberty. London: John W. Parker and Son.

Mondak, Jeffery J., and Mitchell S. Sanders. 2003. Tolerance and intolerance, 1976-1998. American Journal of Political Science 47:492-502.

Noelle-Neumann, Elisabeth. 1974. The Spiral of Silence. A Theory of Public Opinion. Journal of Communication 24(2):43-51.

Petersen, Thomas. 2020. Forschungsfreiheit an deutschen Universitäten: Ergebnisse einer Umfrage unter Hochschullehrern. Konrad Adenauer Stiftung. https://www.kas.de/documents/252038/7995358/ Studie+des+Instituts+für+Demoskopie+Allensbach+zur+Forschungsfreiheit+an+deutschen+Univer sitäten.pdf/01252a6a-38eb-a647-fb74-7d39b1890382?t=1581610619899. Accessed 17 June 2020.

Sachs, Jeffrey Adam. 2018. The 'campus free speech crisis' is a myth. Here are the facts. Washington Post. https://www.washingtonpost.com/news/monkey-cage/wp/2018/03/16/the-campus-freespeech-crisis-is-a-myth-here-are-the-facts/. Accessed 10 Oct 2020.

Stevens, Sean, and Jonathan Haidt. 2018a. The Skeptics are Wrong Part 1: Attitudes About Free Speech on Campus are Changing. Blog Post: Heterodox Academy.

Stevens, Sean, and Jonathan Haidt. 2018b. The Skeptics are Wrong Part 2: Speech Culture on Campus is Changing. Blog Post: Heterodox Academy.

Stevens, Sean, and Jonathan Haidt. 2018c. The Skeptics are Wrong Part 3: Political Intolerance Levels on Campus are High, and Here is Why. Blog Post: Heterodox Academy.

Stevens, Sean T., Paul Quirk, Lee Jussim and Jonathan Haidt. 2017. The Campus Expression Survey. Heterodox Academy.

Stiksma, M. 2020. Understanding the Campus Expression Survey. Heterodox Academy. https://heterodox academy.org/campus-expression-survey/. Accessed 17 June 2020.

Stouffer, Samuel Andrew. 1955. Communism, Conformity \& Civil Liberties: A Cross Section of the Nation Speaks its Mind. Doubleday \& Co.

Strauts, Erin, and Hart Blanton. 2015. That's not funny: Instrument validation of the concern for political correctness scale. Personality and Individual Differences 80:32-40.

Suedfeld, Peter, G. Daniel Steel and Paul W. Schmidt. 1994. Political ideology and attitudes toward censorship. Journal of Applied Social Psychology 24(9):765-781.

Sullivan, John L., James Piereson and George E. Marcus. 1979. An alternative conceptualization of political tolerance: Illusory increases 1950s-1970s. American Political Science Review 73(3):781-794.

Wike, Richard, and Katie Simmons. 2015. Global support for principle of free expression, but opposition to some forms of speech. Pew Research Center 18.

Williams, Jeffrey (ed.). 1995. PC Wars: Politics and Theory in the Academy. New York: Routledge.

Wilson, John K. 1995. The myth of political correctness: the conservative attack on higher education. Durham, N.C: Duke University Press. 
Yglesias, Matthew. 2018. Everything we think about the political correctness debate is wrong. Vox. https:// www.vox.com/policy-and-politics/2018/3/12/17100496/political-correctness-data. Accessed: 10 Oct 2020.

YouGov. 2018. Are Students Really More Hostile to Free Speech? YouGov. https://yougov.co.uk/topics/ politics/articles-reports/2018/06/27/are-students-really-more-hostile-free-speech. Accessed: 2 Sep 2019.

Matthias Revers 1979, Ph.D., Lecturer in Media and Communication, University of Leeds. Fields of research: political polarization through language, right-wing alternative media, digital change and professional culture in journalism, text mining, and qualitative methods. Publications: Contemporary Journalism in the US and Germany: Agents of Accountability. New York: Palgrave Macmillan 2017; The Twitterization of News Making: Transparency and Journalistic Professionalism. Journal of Communication 64, 2014.

Richard Traunmüller 1980, Dr. rer. soc., Professor for Empirical Democracy Research, University of Mannheim. Fields of research: Socio-structural and psycho-cultural foundations of democracy, social cohesion and conflict, freedom of speech and censorship, quantitative methods. Publications: What is Islamophobia? Disentangling Citizens' Feelings Toward Ethnicity, Religion, and Religiosity Using a Survey Experiment. British Journal of Political Science 50, 2020 (with M. Helbling); The Silent Victims of Sexual Violence During War: Evidence from a List Experiment in Sri Lanka. Journal of Conflict Resolution 63, 2019 (with S. Kijweski und M. Freitag). 